\section{Cureus}

Received 01/30/2013

Review began 01/30/2013

Published 01/31/2013

\section{C) Copyright 2013}

Melvin et al. This is an open access article distributed under the terms of the Creative Commons Attribution License CC-BY 3.0., which permits unrestricted use, distribution, and reproduction in any medium, provided the original author and source are credited.

\title{
Acute Chorea in a Child after Starting Methylphenidate: A Case Report
}

\author{
Kelly E. Melvin ${ }^{1}$, Payam Heiraty ${ }^{2}$ \\ 1. Department of Psychiatry and Behavioral Medicine, Marshall University Joan C. Edwards School of \\ Medicine 2. Marshall University School of Medicine
}

$\square$ Corresponding author: Kelly E. Melvin, melvin3@marshall.edu

Disclosures can be found in Additional Information at the end of the article

\section{Abstract}

CNS stimulants are the third most commonly prescribed medication class in the United States for children under the age of 18 . Although they are most often used safely, they can be associated with a number of side-effects, including movement disorders. Acute chorea is a rare but known side-effect of stimulant use that has been primarily described in adults. We present the case of a 10-year-old girl who developed chorea after starting long-acting methylphenidate.

Categories: Family/General Practice, Psychiatry, Psychology

Keywords: movement disorder, cns stimulant, chorea, methylphenidate

\section{Introduction}

Among children up to 18 years of age, CNS stimulants represent the third most commonly prescribed medication class in America [1]. These agents are most commonly used for the FDAapproved treatment of ADHD. Per the Center for Disease Control from 2005-2008, approximately 3.7 percent of individuals in this age range had been taking at least one prescription drug in this class during the previous 30 days. Stimulants are prescribed due to their generally accepted efficacy and tolerability [2]. They are, however, associated with many potential side-effects that include insomnia, depression, reduced appetite, weight loss, headache, visual disturbances, palpitations, dizziness, and many others [3].

Movement-related side-effects from CNS stimulants have long been described and represent a wide array of conditions, including tics, Tourette syndrome, stereotypies, tremor, seizure, dyskinesia, and chorea [4]. Acute sustained chorea is involuntary, non-stereotyped, and hyperkinetic. Choreiform movements have been described in multiple small case reports usually following methamphetamine overdose, supratherapeutic dosing of prescription stimulants, or combining a psychostimulant with a second dopaminergic medication [5-8]. The majority of cases reported describe this phenomenon in adults with relatively few examples in pediatric patients. Ford, et al. presented two cases of acute chorea in children following ingestion of high doses of amphetamine-based medications [8]. Weiner, et al. presented the case of a young child with minimal brain dysfunction who developed chorea in response to therapeutic dosing of methylphenidate [9]. We present the case of a 10-year-old female who developed acute chorea after starting long-acting methylphenidate.

\section{Case Presentation}

A 10-year-old female with a previous diagnosis of bipolar disorder and a long history of 
behavioral difficulties was placed in a sub-acute psychiatric diagnostic program after several failed foster placements. Her initial removal from the biological home was due to parental drug abuse and neglect. On physical examination, the patient was medically healthy with no significant past or current medical illnesses. There was no history of tics, seizures, closed head injuries, or CNS infections. She was 51 inches tall and her weight was 68 pounds. Regarding lab work at admission, her complete blood count, liver function tests, thyroid function tests, and urinalysis were all within normal limits. Her basic metabolic panel showed mildly elevated blood urea nitrogen at 22 and potassium at 4.8. Drug screen was negative and electrocardiogram was read as normal sinus rhythm. At admission, the patient was taking risperidone $1 \mathrm{mg}$ twice daily for a presumed bipolar disorder. Psychological testing and clinical interview showed symptoms of depression and revealed no evidence of bipolar disorder. On day seven, risperidone was decreased to $0.5 \mathrm{mg}$ twice daily for two days and stopped, and she was started on sertraline $25 \mathrm{mg}$ daily. The dose was then raised on day 10 to $50 \mathrm{mg}$ daily. On day 14, the patient was started on long-acting methylphenidate (brand name: Concerta) $36 \mathrm{mg}$ daily to treat ongoing hyperactivity, impulsivity, and distractibility. The patient showed a small but noticeable improvement in symptoms, and on day 18, the dose was raised to $54 \mathrm{mg}$ daily. Shortly after receiving her first dose of $54 \mathrm{mg}$, the patient began to exhibit writhing and irregular hand movements combined with a twisting "dance-like" gait consistent with chorea. She had no localizing neurologic findings on examination and no prodromal symptoms of illness had been reported. Her doses of sertraline and methylphenidate were both held, and she was given lorazepam $0.5 \mathrm{mg}$ twice daily for two days. Within 24 hours, the movements were less pronounced. By day 21, the symptoms resolved completely and her sertraline was restarted with no further complications. A strep screen was obtained at the onset of symptoms and returned as negative.

\section{Discussion}

Chorea is an involuntary, non-stereotyped, and hyperkinetic movement disorder with a large number of potential causes. The disorder can be secondary to an autoimmune process, infection, hypoxic or ischemic injury, mitochondrial disease, or toxin-induced [10-11]. Drugs known to cause chorea include dopamine blocking agents, levodopa, anticonvulsants, calcium channel blockers, oral contraceptives, and psychostimulants [12-13]. Most cases of chorea are thought to originate in the basal ganglia, particularly the caudate or putamen (collectively, the corpus striatum). Imbalances in neurotransmitters, particularly those involving shifts toward excess dopamine, in these areas are thought to be responsible for the abnormal movements of this disorder [8]. Methylphenidate is thought to exert its primary pharmacologic effect by binding to the dopamine transporter and blocking its re-uptake. These actions increase the amount of dopamine available at the neuronal site and are thought to occur most actively in the striatum [3].

Recommended treatment approaches for drug-induced chorea include stopping the offending agent and, if necessary based on severity of symptoms, administration of dopamine blocking agents or benzodiazepines [13]. Given the proposed neurochemical mechanism for the disorder dopamine blockers are considered by many to be first-line.

A probable causal or contributing factor in this case was the high starting dose and relatively rapid titration of drug. The drug manufacturer recommends that children ages 12 and younger start at $18 \mathrm{mg}$ daily and then increase by $18 \mathrm{mg} /$ day every seven days. In previous reports of CNS stimulant-induced chorea, the patient is often exposed to a higher than normal amount of drug whether through prescription, accidental, or intentional overdose.

Long-acting methylphenidate and sertraline are known to interact in such a way that SSRI levels are increased when using the two in combination. It is therefore arguable that the patient's symptoms could be due to the antidepressant. However, this class of medication is not 
known to cause chorea, while stimulants are a well-known offender. It is therefore unlikely that sertraline produced the symptoms in question.

\section{Conclusions}

Chorea is an involuntary, non-stereotyped and hyperkinetic movement disorder with a large number of potential causes. The disorder can be secondary to an autoimmune process, infection, hypoxic or ischemic injury, mitochondrial disease, or toxin-induced [10-11]. Drugs known to cause chorea include dopamine blocking agents, levodopa, anticonvulsants, calcium channel blockers, oral contraceptives, and psychostimulants [12-13]. Most cases of chorea are thought to originate in the basal ganglia, particularly the caudate or putamen (collectively, the corpus striatum). Imbalances in neurotransmitters, particularly those involving shifts toward excess dopamine, in these areas are thought to be responsible for the abnormal movements of this disorder [8]. Methylphenidate is thought to exert its primary pharmacologic effect by binding to the dopamine transporter and blocking its reuptake. These actions increase the amount of dopamine available at the neuronal site and are thought to occur most actively in the striatum [3].

Recommended treatment approaches for drug-induced chorea include stopping the offending agent and, if necessary based on severity of symptoms, administration of dopamine blocking agents or benzodiazepines [13]. Given the proposed neurochemical mechanism for the disorder dopamine blockers are considered by many to be first-line.

A probable causal or contributing factor in this case was the high starting dose and relatively rapid titration of drug. The drug manufacturer recommends that children ages 12 and younger start at $18 \mathrm{mg}$ daily and then increase by $18 \mathrm{mg} /$ day every seven days. In previous reports of CNS stimulant-induced chorea, the patient is often exposed to a higher than normal amount of drug whether through prescription, accidental, or intentional overdose.

Long-acting methylphenidate and sertraline are known to interact in such a way that SSRI levels are increased when using the two in combination. It is therefore arguable that the patient's symptoms could be due to the antidepressant. However, this class of medication is not known to cause chorea, while stimulants are a well-known offender. It is therefore unlikely that sertraline produced the symptoms in question.

\section{Additional Information}

\section{Disclosures}

Human subjects: Consent was obtained by all participants in this study. Conflicts of interest: In compliance with the ICMJE uniform disclosure form, all authors declare the following: Payment/services info: All authors have declared that no financial support was received from any organization for the submitted work. Financial relationships: All authors have declared that they have no financial relationships at present or within the previous three years with any organizations that might have an interest in the submitted work. Other relationships: All authors have declared that there are no other relationships or activities that could appear to have influenced the submitted work.

\section{References}

1. National Center for Health Statistics. Health, United States, 2011: With Special Feature on Socioeconomic Status and Health. Health, USA, Hyattsville; 2012.

2. Hodgkins P, Shaw M, McCarthy S, Sallee FR: pharmacology and clnical outcomes of amphetamines to treat ADHD: does composition matter?. CNS Drugs. 2012, 26:245-268. 10.2165/11599630-000000000-00000 
3. Prommer E: Methylphenidate: established and expanding roles in symptoms management. Am J Hosp Palliat Care. 2012, 29:483-490. 10.1177/1049909111427029

4. Lopez W, Jeste DV: Movement disorders and substance abuse. Psychiatr Serv. 1997, 48:634636.

5. Sperling LS, Horowitz JL: Methamphetamine-induced choreoathetosis and rhabdomyolysis. Ann Intern Med. 1994, 121:986. 10.7326/0003-4819-121-12-199412150-00019

6. Morgan JC, Winter WC, Wooten GF: Amphetamine-induced chorea in attention deficithyperactivity disorder. Mov Disord. 2004, 19:840-842. 10.1002/mds.20081

7. Vytopil M, Mani R, Adlakha A, Zhu JJ: Letters to the editor: Acute chorea and hyperthermia after concurrent use of modafinil and tranylcypromine. Am J Psychiatry. 2007, 164:684.

8. Ford JB, Albertson TE, Owen K, Sutter ME, McKinney B: Acute, sustained chorea in children after supratherapeutic dosing of amphetamine-derived medications. Pediatr Neurol. 2012, 47:216-218. 10.1016/j.pediatrneurol.2012.05.013

9. Weiner WJ, Nausieda PA, Klawans HL: Methylphenidate-induced chorea: case report and pharmacologic implications. Neurology. 1978, 28:1041-1044. 10.1212/WNL.28.10.1041

10. Wild EJ, Tabrizi SJ: The differential diagnosis of chorea . Pract Neurol. 2007, 7:360-373. 10.1136/pn.2007.134585

11. Kirkham FJ, Haywood P, Kashyape P, et al: Movement disorder emergencies in childhood. Eur J Paediatr Neurol. 2011, 15:390-404. 10.1016/j.ejpn.2011.04.005

12. Singer C: Comprehensive treatment of Huntington disease and other choreic disorders . Cleve Clin J Med. 2012, 79:30-34. 10.3949/ccjm.79.s2a.06

13. Gilbert DL: Acute and chronic chorea in childhood . Semin Pediatr Neurol. 2009, 16:71-76. 10.1016/j.spen.2009.03.009 